\title{
We the Peoples. A Rawlsian Perspective of International Justice
}

\author{
Juan Antonio Fernández Manzano \\ Complutense University of Madrid
}

This text analyses the possibility of discussing global justice today using the theoretical tools of John Rawls. With that end in mind, we will present the main lines of his justice as fairness to see how Rawls extrapolates the fundamental bases of his theory of justice at a global level.

Having done that, we will evaluate the theoretical justification of the Rawlsian global approach, its internal consistency and its validity in practice to conclude that the Rawlsian defense of the autonomy of peoples prevents his theory to properly set limits on global inequalities. By replacing the redistributive potential of the domestic difference principle by a meager duty of assistance, Rawls's theory is quite permissive with global material inequalities, which can be considered an inconsistency.

Keywords: global justice, duty of assistance, inequality, peoples

The issue of global justice can be considered one of the most philosophically relevant, at least within the area of practical philosophy, and it is at the same time a politically pressing issue, perhaps the most urgent. We can say, without fear of being mistaken, that we do not live in a just world. In fact, this might be, as Nagel (2005) puts it, one of the least controversial claims one could make in political theory, that challenges us both as thinkers and as citizens.

Indeed, despite the increase in global wealth, there is still a majority of people on the planet without access to the most basic means of subsistence: food, clean water, sanitation, clothing, housing or material goods, in stark contrast to the opulence of other countries. Global inequality between countries is evident and well known: North America and Europe, with only 17\% of the adult population of the planet, hold 55\% of the total global wealth. Internal inequalities within countries are also considerable: the usual is between $25 \%$ and $40 \%$ of all the wealth in a country is in the hands of the richest $1 \%$. And if we talk about the richest globally, $1 \%$ of billionaires accumulate $43.4 \%$ of net global wealth, while $90 \%$ of the global population has to settle for $19 \%$ of global wealth (Credit Suisse Research Institute, 2020). The outlook for the millionaire segment is expected to rise by 22 percent, from 36 million people in 2017 to 44 million in 2022. However, the most disadvantaged are expected to shrink by only 4 percent. (Credit Suisse Research Institute, 2017).

It was John Rawls who, with his The Law of Peoples (1999), presented the bases that inevitably arise when discussing global justice. The question that drives this text is the possibility of thinking about global justice using the theoretical tools and the legacy Rawls left us. With that end in mind, we will present the main lines of his justice as fairness (I) to see how Rawls extrapolates the fundamental items of his theory of justice at a global level and why (II). Having done that, we will evaluate the theoretical justification of the Rawlsian global approach, its internal consistency and its practical validity (II). 
Rawls developed his theory of justice, justice as fairness, mainly to approach a common problem in contemporary societies: the arrangement of cooperation among plural individuals within the political framework of a democratic constitutional state. His theory aimed to provide both methodological instruments and material principles that if applied to the institutional configuration of any society (the "basic structure" in Rawlsian terms), citizens would consider they live in a just society. A well-ordered society, as Bodin said, which everyone could voluntarily adhere to, despite their different backgrounds, contingencies, features, ideas and doctrines.

This approach can be easily understood if we recall the context in which Rawls wrote his theory of justice. The 1960s in the United States was one of the most vibrant and turbulent periods in its social history. It was the time when the activism of new social actors burst onto the political scene: the Afro-American population, pacifist and feminist organizations, student movements, the hippie counterculture, etc. All of them, in one way or another, sought greater social transformation, equal rights and social and cultural changes that were opposed to some of the values of the more conservative hegemonic sectors: McCarthyism, the persistence of racial segregation, Judeo-Christian values, anti-communism, American exceptionalism, etc. (Ríos, 1998). The sociological conditions that allowed his theory to emerge can be found in the postwar years and under the impact of the Vietnam War (Forrester, 2019, p. Xi). In this convulsive climate of pluralism and doctrinal heterogeneity, in order to reach the "overlapping consensus" it was necessary to define on which issues, of the many that divide citizens, it is necessary to reach an agreement. Rawls responds by stating that the questions of basic justice that will become constitutional essences are those that urgently need to be agreed. Therefore, the overlapping consensus is a reductively political agreement, capable of removing from the agenda the issues that can generate violent conflicts that could undermine the foundations of social cooperation. A stable political agreement must set aside metaphysical-religious doctrines (the "comprehensive doctrines") and focus on those aspects of justice that must be addressed first. In other words, a limited agreement to the principles of political justice that should govern the basic structure of society. The contents of such agreement will limit to what rights and freedoms are essential and how they are allocated, how far tolerance should extend, how to reconcile values such as equality and freedom, the division of wealth and benefits originated over time, how posts are distributed within that society or how much social inequality is permissible.

These are the fundamental questions that allow any society to become a stable framework for cooperation. Now, to overcome the pitfalls involved by the presence of different criteria to address these issues, it is necessary to establish a method considered fair by all parties. A method whose results were, given the fairness of the proceedings, also equitable, so that no one could, if the procedure is accepted, reasonably reject them. If so, we would have reached the desired "overlapping consensus" with which society, despite their doctrinal plurality, could operate fairly and with the confidence to last over time. As it is known, Rawls mainly uses the social contract methodology. The objective: to reach a fair agreement between free and equal people whose resulting principles of justice treat everyone not depending on who they are, but as they would treat anyone else. The method: to generate a position not distorted by the particular interests of anybody, an impartial and neutral perspective. This view appears with the hypothesis of the original position that leads to clarifying the principles of justice. To use this useful heuristic mechanism, Rawls asks us to imagine a sort of hypothetical initial unhistorical agreement, in which contracting parties concur as representatives of citizens, duly devoid of any information that could compromise their impartiality. Under this "veil of ignorance", the parties become unaware of their origin, ethnicity, religion, social class, wealth, talents and skills, etc. and can get to agree on fair terms with which to organize social cooperation. The first principle of justice Rawls stipulates that every person has an equal right to a fully adequate scheme of equal basic liberties compatible with a similar scheme of liberties for all. That is, the same non-negotiable freedoms and rights for everyone: personal integrity, protection against psychological or physical aggression, the right to personal property necessary for subsistence, independence and freedom of thought and conscience, freedom of expression and assembly (Rawls 1999a: 53), freedom from arbitrary arrest and detention and the rights and freedoms protected by the rule of law. Similarly, political freedoms, including the right to vote and to be eligible for public office, the right to equal political participation, the right of association, militancy, expression, critical and political demonstration are also 
included. There is no reason why anyone can aspire to more than any other in any of these fields. The second principle states that social and economic inequalities are to be permissible if they meet two conditions: a) they must be linked to positions and posts open to all under conditions of fair equality of opportunity (principle of equal opportunities) and b) must be to the greatest benefit of the least advantaged in society (the difference principle) (Rawls 2005: 291).

As already indicated, the framework of the theoretical and practical application of the theory of justice of Rawls is limited to the boundaries of the nation-state, what he calls a closed and self-sufficient society, isolated from other societies, in which individuals enter at birth and exit when they die.

Rawls justifies this limitation of his theory of justice based on methodological reasons. It is, as he recognizes, a considerable abstraction, justified by the fact it allows us to concentrate on major issues without getting lost in details. It also seems justified by the fact that no theory can capture reality in all its complexity. This is why it is necessary, at least at first, to present models which, despite its simplicity, serve to represent a more complex reality. Rawls states that he will begin with the basic structure of one society as a closed and self-sufficient system of cooperation and should he find a suitable conception for this case, then he could work outward to the law of nations.

In any case, Rawls recognizes that sooner or later, it is necessary to leave this abstraction and address the "problems of extension".

Being a systematic thinker, Rawls was expected to complete his theory and develop these areas in subsequent work. Basically there were four issues that his theory of justice left unaddressed and that, according to Rawls himself, merited an individualized treatment: how to extend justice to future generations (the problems of just saving and the legacy left to future generations); how to extend justice to those individuals who are not in a position to be fully cooperating members of society (people with disabilities, disease, people who have suffered accidents...); how to extend justice to non-human animals and the natural environment and finally, how to extend justice to international relations between political societies. Among these, and due to lack of time for a proper treatment, Rawls addressed only one: the last. It was his attempt to complete his thought, leaving other thinkers the task of developing the remaining three.

Addressing the issue of justice in international relations went through three phases: an incipient already appeared in his $A$ Theory of Justice (1971) in section 58, limited to the debate on just war and conscientious objection. He wondered at that point whether it was possible to extend the interpretation of the original position and think of the parties as representatives of different nations who must choose together the fundamental principles to adjudicate conflicting claims among states (Rawls 1999a: 333). In section 58, Rawls posited some of the principles that should govern relations between nations. A second phase came with the article entitled "The Law of Peoples" (1993), which in 35 pages outlined the main arguments of his theory.

Finally, the last phase would come with his book The Law of Peoples (1999b), which develops the theme, using its own terms, in a "more complete and satisfactory" way (Rawls 1999b: 9).

Reactions went mostly from bewilderment to disappointment, mainly due to the lack of connection between his theory of justice, developed in A Theory of Justice (1971), Political Liberalism (1993) and Justice as Fairness (2001), and its extension to the international level.

What the 1993 article announced and the 1999 book came to confirm is that Rawls, almost thirty years after his $A$ Theory of Justice, was unwilling to apply the same principles to both realms.

Those expecting a theory of international justice in a cosmopolitan key were disappointed. It was surprising that a thinker with the radicalism of his demands for justice at the local level desisted from its extension beyond state borders (Williams 2014).

However, perplexity is not a bad start. From the origins of philosophical thought, wonder has been the most basic emotion related to philosophy. In any case, going beyond the perplexity and given the lack of symmetry between domestic and global principles, the relevant question is whether this work deserves the consideration of those involved in Rawlsian thought or whether on the contrary it should be forgotten (Williams 2014). 
The most basic question is why those principles that apply in a small political context would not be applicable to a larger political context? Why did not Rawls hold the validity of its principles or its methodology?

One of the keys to understanding this shift lies in the decision Rawls stated at the beginning of his 1999 work. He would develop his international theory based on the concept of peoples. This decision may seem obvious and unquestionable since the title of the work is precisely The Law of Peoples, but it is not, as we will try to show.

Rawls makes his work revolve around the concept of "people" or "peoples", which in principle he wants to distinguish from "nations" or "states" (Rawls 1999b: 9). The peoples resemble states as both have their own governments, but are distinguished from these because peoples lack complete sovereignty, neither internal nor external. They cannot act internally without respecting human rights and are not entitled to unilaterally declare war on other peoples. What distinguishes peoples from states, says Rawls, is that just peoples are fully prepared to grant the very same proper respect and recognition to other peoples as equals (Rawls 1999b: 35).

Beyond these differences, the concept of peoples is a poorly defined idealization, halfway between nation and state, as a sort of moralized form of state, able to establish reasonable relations, not only rational, with other peoples (Brock 2010).

Consistent with this approach, the ultimate goal is the creation of a society of reasonably fair peoples. This society of peoples would be composed of all those people who subscribe to and respect the ideals and principles of international law in their mutual relations. The law of peoples ought to be understood not as all laws that different peoples share, but as the political principles that they all subscribe. The ultimate purpose would be, however unlikely that may be, the inclusion of all peoples in a global society of peoples (Rawls 1999b: 13-15).

What we want to emphasize is that Rawls is dealing with political communities, nations or peoples, because these are the ones that in his opinion deserve moral relevance. The underlying assumption is that peoples are responsible for imparting justice and ensuring the rights and freedoms of their own citizens in their own territory. The peoples are then the subjects who legislate and on which the global political principles apply. It is the political communities, and not the individuals, the relevant actors of this theory. The peoples are taken as free and equal. The pluralism previously applied to individuals, and the related concept of tolerance, are both transferred to peoples now (Williams 2014).

The influences of Kant in these lines can be identified very clearly. The idea of international law, said Kant in Perpetual Peace (1795), starts from the separation of many neighbor states which are independent, have different languages and religions and cohabit in the absence of rules, which might cause the outbreak of hostilities.

Whether we call them people, states or nations, the selected methodological starting point is very similar to Kant's and it has important implications for the theory.

The first idea we would like to highlight takes us to the domestic theory of justice. Here, individuals were considered the atom of any political society. This point obviously does not require further justification: societies are composed of individuals and these are the ones who should be properly represented in the original position in order to establish the principles around which social cooperation is to be organized.

However, when Rawls starts his theory of international justice, he abandons the idea that individuals are the basic point of reference.

It is true that the world is made up of peoples, mostly organized in states and nations, but it is not so obvious that the original position has to assume uncritically that the peoples are the parties of such starting position.

Rawls's decision has direct consequences on the functioning of the hypothetical original position with which Rawls proposed that we should identify the principles of justice under the veil of ignorance (Rawls 1999a: 15-19; 2001: 80-83).

If domestically, Rawls employs a unique original position in which the parties that represent citizens, agree on fair terms of cooperation that will shape the basic structure of their society, the law of nations introduces several original positions which depend on his categorization of types of peoples. 
This is a contrast with his original theory, in which, in spite of all their differences, individuals were treated all alike.

A first original position, the one we were familiar with, would be carried out by the representatives of citizens who belong to a liberal reasonable people (a liberal democracy). This original position is meant to establish the principles of domestic justice already known.

The second position would be among different liberal peoples which elucidate and agree on the principles of international law to be applied in their external relations. The outcome of such agreement of liberal democratic societies would be the contents of international law which, according to Rawls, would be the adoption of the following principles: 1. Peoples are free and independent. Their freedom and independence are to be respected by other peoples. 2. Peoples are to observe treaties and undertakings. 3 . Peoples are equal and are parties to the agreements that bind them. 4. Peoples are to observe a duty of nonintervention. 5. Peoples have the right of self-defense but no right to instigate war for reasons other than self-defense. 6. Peoples are to honor human rights. 7. Peoples are to observe certain specified restrictions in the conduct of war. 8. Peoples have a duty to assist other peoples living under unfavorable conditions that prevent their having a just or decent political and social regime (Rawls: 1999b: 37).

The first thing that stands out is the absence of principles that refer to equal opportunities or which deal with the distribution of goods and wealth. We will refer to these absences.

The third original position is the one which involves liberal and the so-called "decent hierarchical peoples", those who are not aggressive with other peoples, respect the human rights of their members, and that in spite of not being democracies, have a "decent consultation hierarchy". Appealing to a combination of both realism and tolerance, Rawls argues that these peoples must be accepted as members in good standing in a reasonable Society of Peoples despite not recognizing freedom of expression, association or the rights of political participation.

Both democracies and decent hierarchical peoples can be considered well-ordered peoples and are expected to agree on the same contents of international law liberal peoples agreed together previously.

The other three kinds of peoples: outlaw states, societies burdened by unfavorable conditions and benevolent absolutisms are denied a role in the agreement until their circumstances change. The first would not accept the principles of international law; the ones burdened by historical, social and economic circumstances have enormous difficulties to establish a well-ordered regime and the third, benevolent absolutisms, respect the human rights of their members but deny their right to participate in political decisions.

The difference principle and the effective measures of equality of opportunities disappear. Instead, we find the "duty of assistance". According to this principle, liberal or decent peoples have the duty to assist burdened societies so that these are able to establish their own just institutions.

They should assist them to improve their cultural competence in a broad sense: including technology, knowledge, techniques... so that they have all the tools to become a well-ordered self-sufficient society. The purpose of the aid, and its limit, would be to make these people stand up so that they have the ability to conduct their own affairs properly and to become part of the group well-ordered peoples. Once this aim has been achieved the assistance would cease.

This is one of the most notorious differences between the domestic and the global theory. For Rawls, the existing compromise between compatriots is not the same as the one among citizens of the world.

What is owed to other people is not the equalization of opportunities or the distribution of wealth or resources but the promotion of their autonomy as independent peoples, regardless of differences in the welfare of citizens from different peoples.

We can only understand this position as derived from the implicit belief in the primacy given to nationals. The treatment given to those closer to us includes a bigger commitment to their welfare which is manifestly above what is due to others (Sen 2009).

This is something which should not surprise anyone: identities, commitments and loyalties develop, as Aristotle said, starting from the closest areas, first comes the family and then the tribe, the village and from this to the polis. As the circle narrows, the intensity of the affinities and moral concern increases, which in turn decrease with the distance (Appiah 1996). 
This seems to be an unquestionable fact: we tend to operate better at short distances and we feel more identified with relatives and neighbors than with abstractions like the idea of humanity. This implicit assumption leads Rawls to support the replacement of the difference principle for a reduced duty of assistance. Besides, there are two other explicit reasons, which we will synthesize in two concepts: autonomy and political culture.

The autonomy of peoples is a central value of paramount importance in Rawls's philosophy. Rawls attributes to peoples, treating them as a collective subject with ontological reality, qualities that fit with some of the values traditionally defended by individualistic liberalism. Peoples desire independence, they want to be self-sufficient and they consider that their dignity is impaired if they receive external help, which is normally considered as a paternalistic treatment. Peoples assume responsibility for their autonomy and do not require anything from the rest (Rawls 1999b: 44). The self-respect of peoples depends largely on their capability to accept their fate and do whatever they can to succeed without any help. Therefore, beyond the duty of assistance owed to peoples burdened by unfavorable conditions, peoples can have no other legitimate claims to others to foster their well-being and have to accept there are no reasons to promote further reduction of material inequalities among societies (Rawls 1999b: 119).

Besides autonomy, political culture is the second argument Rawls employs to support the replacement of the difference principle for the duty of assistance.

Political culture, related to moral learning, is the second key concept in Rawls's theory. For Rawls, material resources are not relevant to the prosperity of a people. Wealth is mainly achieved thanks to the political culture of a society. Obviously, to reach this political autonomy certain material goods are needed, mainly to avoid desperate situations, but once this is overcome with the duty of assistance, everything depends on the political wisdom of the peoples. Therefore, there are no reasons to defend the difference principle. Once the peoples have achieved a decent government, there are no attempts to narrow the gap between the average wealth of different peoples, because Rawls insists that most differences in wealth are attributed to domestic factors and not to external ones.

Rawls gives extraordinary importance and potential to the industriousness of peoples, to their ability to overcome obstacles, their political values, their ability to organize themselves, their institutions, their political and cultural traditions, their human capital, their know-how and ultimately their moral learning. As we can see, all of these are nonmaterial aspects that could be, in principle, available to anyone. These values have the capacity to cushion or overshadow the greater or lesser amount of material goods. Rawls seems to believe that the lack of material resources can be compensated by endogenous factors such as the resourcefulness and ingenuity of those affected by poor material conditions.

His examples highlight how certain countries with a low per capita income are able to provide better public services to their citizens thanks to their democratic mechanisms and the absence of corruption.

This may seem incontestable. Surely a democratically organized people tend to fight against minorities wishing to gain power and resources illegitimately. It is reasonable to suppose that strong democracies will employ much of their material resources to meet the basic needs of their citizens.

However, the domestic basic structure of a people does not seem to be, in a global context, crucial to ensure that their citizens have the necessary material resources to play with equal opportunities and conditions in competitive arenas such as the present global markets.

The above-mentioned appeals to autonomy and political culture connect with much of the neoliberal ideology, according to which prosperity depends on the attitudes of individuals more than on external circumstances such as material status. In an exercise of lack of sociological imagination, this ideology states that any individual or group can get everything they want if they try to achieve it hard enough.

The reverse of this thesis is that, as we know, the weight of responsibility of marginalization or poverty is borne on the backs of the disadvantaged, so that the punishment they receive is twofold (Biagini \& Fernández 2013).

In this perspective, we certainly miss a more lucid gaze that could capture the broader scenario and how different forces have the power to gravely affect the vital paths of both peoples and individuals. This is what Charles Wright Mills (1959) called the connection between biography and history. This approach 
would lead us to ask, for example, if we can seriously state that the causes of poverty and dependency suffered by a number of peoples can be exclusively attributed to endogenous conditions.

One of the main advantages of the genuine original position is that the parties could have the strong conviction that once the veil of ignorance with which they negotiated is removed they could accept to live in any post and position in that society. The fact of being responsible for the principles under the conditions of the veil of ignorance made them assume that even if they were in a disadvantaged position, it would have been chosen by them as the lesser evil, once considered all possible scenarios.

We believe it is very relevant Rawls's insistence on this point in his theory of justice, especially in the section that refers to the strains of commitment.

There are two premises: the first is that the agreement is formalized without the possibility of reopening it. What has been agreed upon is not going to be rediscussed later, the agreements are sealed in perpetuity. The parts choose, once and forever, the guidelines that are to govern their life prospects and there are no second chances. This premise requires the parties to weigh and consider carefully the justice of the principles to be selected.

The second premise Rawls employs is that for an agreement to be valid, the parties must be able to be ready to fulfill it in all foreseeable circumstances. No one can, in good faith, sign an agreement that could give rise to obligations whose weight was unenforceable or whose compliance could generate marginalization, resentment, oppression or gave rise to hostility, protests or violent actions from those in socially disadvantaged position (Rawls 2001: 128).

Again, this condition makes it necessary to adopt principles that do not generate a commitment whose rigor is intolerable for anyone (Rawls 1999a: 153).

The test of commitment that Rawls proposes: to unite the final character of the covenant and to assert the impossibility of making legitimate complaints once the veil of ignorance is lifted, leads to ensure that inequalities must be sufficiently justified, so that even the worst off can admit that their position is the best possible once weighed the different theories of justice.

The strong tendency to equality of the genuine original position or, at least, the meticulous justification of inequalities between citizens, obliged the parties to fix the focus on the weakest links in the chain. This tendency and these thoughtful considerations are not observed when the theory is extrapolated to the society of peoples.

If Rawls had decided to maintain the premises of the original position and the test of the strains of commitment, he would have applied the veil of ignorance to the parties with respect to their people of origin, so that there would not be several original positions, but a single one (Barry 1973, Beitz 1979). It is difficult to accept the test of commitment for those whose life choices, life expectancy and any kind of development are hindered by the contingency of having a particular nationality. The veil of ignorance has to be as dense as possible when choosing the principles of justice, less dense in the constitutional moment, and even less in the legislative and judicial stages. In every moment of the four steps, more contextual information is required to impart justice.

Precisely, the use of the veil of ignorance, maximally dense at the time of choosing the principles of justice, prevented parties to lean on inappropriate or irrelevant reasons (Rawls 1999b: 31).

It seems clear that nationality, as well as being an accident, is a morally irrelevant factor in order to establish the principles of justice. At least, just as irrelevant as the rest of the factors hidden behind the original veil of ignorance: social class, wealth, talents, knowledge about personal identity, place in society, beliefs, etc. If the fact of belonging to an ethnic group is not a condition that should be considered when allocating rights, freedoms and property, we do not see why membership to a particular people ought to be treated differently (Nussbaum 1996).

The exclusion of the factor of nationality of what is hidden by the veil of ignorance is the cause of the subsequent division in the types of people described above and causes the introduction of an unacceptable particularist bias.

Without the full implementation of the veil of ignorance to all contingencies, the theory is biased and cannot be taken to its logical conclusion, losing the radical depth of the preceding works. 
The original position of the second stage ceases to be an impartial position to become a sort of neutral summit of heads of states. We say neutral because at least there is no position of strength and all parts are placed in a symmetrical position. Parts do not know their territory size, population, the power of their people, natural resources and economic development. But the problem is that they do know that their resources, goods and riches are not discussed or distributed (Rawls 1999b: 33).

In addition, the parties do not forget that they must defend the interests of the people they should return to and that among these interests is to maintain the independence of their own society (Rawls 1999b: 41). Rawls assumes that the representatives of the people are mainly interested in satisfying the welfare of their citizens and seem disinclined to work on a democratic scheme of global cooperation. By a democratic scheme of global cooperation we imply the possibility of redistributing wealth according to democratic criteria, the possibility of discussing the territorial extension of peoples, the discussion of the question of the access to natural resources and the consideration of equality of opportunities for all citizens of the world.

Rawls could support his theory and his option for the people by stating that the fact of the existence of states cannot be forgotten and no one can doubt their current and future importance (Beitz 1979: 8). Individuals do not live in a vacuum, they are always embedded and rooted in political structures in operation.

This is true, states or peoples, are morally relevant and worthy of consideration due to the fact that they are important to individuals.

Peoples are the primary locus in which individuals develop. Individuals usually tend to develop their identities and loyalties in small communities. As politically organized entities, states are also important because they are primarily the guarantors of the rights and freedoms of citizens. Therefore, it would be unreasonable to argue, for the sake of global justice, for the disappearance of state political structures.

However, this does not mean, and this is the critical point, that the primary moral commitment is the one individuals owe to the local community in which they develop.

The most defensible moral compromise is that owed to the idea of justice, and this commitment, as Rawls stated in his earlier writings, cannot be subordinated to local loyalties. Considerations taken with regards to the idea of justice should always take precedence in case of conflict (Gutman 1996). Therefore, the hierarchically superior loyalty, which deserves primacy in terms of justice, is the loyalty due to the human community at large. The claims of the distant others are, ceteris paribus, as equally valid as any other and their interests worthy of the same consideration as the interests of those coming from our own people.

There are no moral grounds to claim the primacy of our people over the interests of the members of any other peoples (Nussbaum 1996; Sen 1996).

The Declaration of Human Rights proclaims that it is individuals, all members of the human family, not their political communities, the ones whose dignity deserves equal recognition.

In any case, both loyalties are not mutually exclusive. Defending the primacy of the interests of humanity over the interests of the peoples we belong to does not mean that local loyalties ought to be excluded. Primacy is not synonymous with exclusivity. Affirming that the fundamental loyalty is due to any citizen of the world does not mean denying any sensitivity to the structures closer to individuals in the local, state or regional circles. Both loyalties can be largely reconcilable without interference. However, in case of conflict, the cosmopolitan perspective has the moral primacy (Nussbaum 1996; Sen 1996).

But Rawls did not accept this approach. Instead, he located the peoples, not the individuals, as the core of his theory. By doing so, he placed the peoples on the highest step of the hierarchical primacy, leaving individuals in a secondary place.

He forgot that individuals are the weakest link in the chain. Let us consider that insecurity, poverty and food shortages affect individuals, not peoples. Even if we considered that poverty affects peoples too, it is necessary to distinguish that not all individuals within a people suffer from it alike. Inequalities within states cannot be dealt with unless the primary focus is placed on individuals.

It is individuals, and not peoples, who have the capacity to suffer regardless of their belonging to different political entities. 
So here we have two different criteria: the concern for individual suffering and the respect for the organizational autonomy of peoples. Rawls chose the second.

Under the autonomy of peoples, Rawls's theory maintains, slightly attenuated by the duty of assistance, the current pattern of global inequality.

The choice of peoples as parties in the original position acts as an intermediate filter that prevents the extension of the symmetry derived from the original position to reach individuals. From its origins, liberalism accepted a theoretical commitment, not always honored in practice, to the equality of all individuals. To place the equality of the peoples over the equality of individuals is against that liberal starting point.

John Stuart Mill, one of the hallmarks of liberalism, insisted on the idea that individuals are the core elements of the system and that the interest of the community cannot subordinate their particular interests.

Rawls's defense of peoples is a change in this line of thought which deviates both from genuinely liberal positions defending the primacy of the individual and also from cosmopolitan positions which, accepting the liberal primacy of individuals and their inviolability, extend this primacy to defend the equal rights of all members of humanity.

Rawls places his theory in a no man's land, refusing to accept the validity of the thesis of the primacy of individuals he supported before.

In conclusion, Rawls did not take the radicalism of his previous thought to its logical conclusion, which can only be considered as an inconsistency (Beitz 2000; Buchanan 2000; Caney 2002). What Rawls presents, paradoxically, it is not so much an extension of the theory of justice but the reduction of the very idea of justice (Sen 2009).

It is disappointing that Rawls's proposal, which aims to defend a conception of fairness and justice applicable to law and international practice (Rawls 1999b: 3), has not gone further in their approach and have fostered a more cosmopolitan approach.

However, we cannot forget two of the main lines of argument in defense of this change in the Rawlsian approach. These are based on two arguments to which Rawls appeals on several occasions: a) its proposal improves the existing order of things and $b$ ) is an exercise of realism.

The first argument is that the application of international law based on his premises would help harmonize relations between states, reduce the danger of military conflicts and would be an improvement in international relations, marked at present by power relations and conflict. His proposal would introduce reforms that would change the status quo and would also alleviate the extremely poor conditions in many countries of the world.

The second argument is that his theory is a "realistic utopia" that takes, as Rousseau said, people as they are and laws as they may become (Rawls 1999b: 13). In line with realism, some critics argue that Rawls's claim was modest: he did not intend to elucidate a theory of global justice, but the lines that should guide the foreign policies of liberal states in their mutual relations and their relations with non-liberal states (Freeman 2006). His work should be understood not in the orbit of the theory of justice but of international relations (Williams 2014).

With regard to the first argument, we can accept that the applications of his theory would certainly be an improvement in the current global situation, but what the original position defends, and this is the core of his theory is that, based on the equal consideration of interests of all parties, they can reach agreements that pass the test of commitment, which is certainly a more demanding and satisfying criterion.

Could the test of commitment be passed under Rawls's conditions? It seems difficult to admit it if no radical changes are made regarding peoples' power or wealth.

It would have been desirable that a great thinker like Rawls, especially when he was aware that this work culminated his reflection on justice (Rawls 1999: 10), had championed the cause of a global cosmopolitan justice which, as we have tried to show, would be in line with his previous work. The inconsistencies of philosophers are all the more reprehensible the greater the intellectual power of the thinker. 
With regard to the second argument, based on the Rawlsian realism, we can highlight something too. This argument defends that it is necessary to lower the height of expectations of a theory and prefer a stable and secure world to a just world.

Stability and security are undoubtedly desirable goals but lasting peace and security seem unlikely in an environment that is not just (Brock 2010). A seriously unequal division of wealth is a deep threat to a stable political community (Kelly 2014).

The problem with this kind of realism is that it is an approach that leaves untouched a number of issues that are fundamental preconditions of justice.

As we have seen, Rawls starts from already formed peoples and places these as the legitimate contracting parties of a society of states in which individuals are relegated to the background. This position forces him to change the original position, which in turn leads to the promulgation of the eight principles in which economic redistribution, among other things, is absent.

Thus, the redistributive potential of difference principle disappears and is replaced by a meager duty of assistance, quite permissive with material inequalities between peoples (Miller 2014). The defense of autonomy prevents his theory to properly set limits on global inequalities. Besides, the debate on the right to emigrate and how porous the boundaries of states should be is also forgotten.

The insistence on the importance of political culture makes him undervalue the importance of the material sources of wealth, such as energy resources. There is no attempt in his writings to develop a theory of justice to address the question of the ownership and distribution of the natural resources of the planet.

The global dynamics of production and the environmental degradation are not analyzed in depth either. Therefore, what the alleged realistic approach really does is focus on one part of the problem of global justice failing to grasp the issue at its greatest extent.

This is not a minor fault. As Plato said, the crucial elements of justice are better observed on the larger scale (Rep. 369a). It is a mistake to judge the justice of a part if we do not analyze the broader scenario in which that part is inserted.

Fair relations between states cannot be addressed with rigor if the whole issue of global justice does not arise.

The methodology centered on peoples takes for granted and does not dispute the existence of states, their territorial extension, the natural resources or the means available to each of the peoples.

By doing so, Rawls is implicitly legitimizing the prevailing status quo and validating the current economic policy that governs the world.

The problem is that what Rawls called realism becomes an uncritical acceptance of much of the current global order we considered unjust ant the beginning of these lines.

Neither the law of peoples nor the duty of assistance question global economic policies or the interests they serve.

This theory does not analyze to what extent these policies generate the dependency situations the duty of assistance aimed to remedy.

Before dealing with the implementation of the duty of assistance it is necessary to investigate the causes that make peoples need such assistance. The justice of the relations of production ought to be discussed before dealing with redistribution.

To try to alleviate extreme injustices, crippling poverty and inequalities by applying minor adjustments which leave untouched the capitalist shaping the world with the economic and financial forces at play is an exercise either of naive voluntarism or a covert legitimization of structures whose legitimacy has not undergone democratic scrutiny.

\section{REFERENCES}

Appiah, K.A. (1996). Cosmopolitan Patriots. In M.C. Nussbaum \& J. Cohen, For love of country? Boston: Beacon Press.

Barry, B. (1973). John Rawls and the Priority of Liberty. Philosophy and Public Affairs, 2, 274-290. 
Beitz, C. (1979). Political Theory and International Relations. Princeton: Princeton University Press. https://doi.org/10.1086/233369

Beitz, C. (2000). Rawls's Law of Peoples. Ethics, 110, 669-696.

Biagini, H.E., \& Fernández, D.A. (2013). ¿Neoliberalismo o neuroliberalismo? Emergencia de la ética gladiatoria. Utopía y Praxis Latinoamericana, Revista Internacional de Filosofia Iberoamericana y Teoría Social, 18(62), 13-34.

Brock, G. (2010). Recent Work on Rawls's Law of Peoples: Critics versus Defenders. American Philosophical Quarterly, 47(1), 85-101. Retrieved from http://www.jstor.org/stable/40606904

Buchanan, A. (2000). Rawls's Law of Peoples: Rules for a Vanished Westphalian World. Ethics, 110, 697-721. https://doi.org/10.1086/233370

Caney, S. (2002). Survey Article: Cosmopolitanism and the Law of Peoples. Journal of Political Philosophy, 10, 95-123.

Credit Suisse Research Institute. (2017, November). Global Wealth Report 2017: Where Are We Ten Years after the Crisis? Retrieved April 18, 2019, from https://www.creditsuisse.com/corporate/en/articles/news-and-expertise/global-wealth-report-2017-201711.html

Credit Suisse Research Institute. (2020, October). Global Wealth Report 2020, October. Retrieved January 30, 2021, from https://www.credit-suisse.com/media/assets/corporate/docs/aboutus/research/publications/global-wealth-report-2020-en.pdf

Freeman, S. (2006). The Law of Peoples, Social Cooperation, Human Rights, and Distributive Justice. Social Philosophy and Policy, 23, 29-68. https://doi.org/10.1017/s026505250606002x

Gutman, A. (1996). Democratic Citizenship. In M.C. Nussbaum \& J. Cohen (Eds.), For love of country? Boston: Beacon Press.

Kant, I. (1795). Zum ewigen Frieden (Ein philosophischer Entwurf). https://doi.org/10.1007/978-3-53190400-9 54

Kelly, E.I. (2014). Inequality, Difference and Prospects for Democracy. In J. Mandle \& D.A. Reidy (Eds.), A Companion to Rawls (First Edition). Chichester, West Sussex: John Wiley \& Sons. https://doi.org/10.1086/678369

Miller, R.W. (2014). Global Poverty and Global Inequality. In J. Mandle \& D.A. Reidy (Eds.), A Companion to Rawls (First Edition). Chichester, West Sussex: John Wiley \& Sons. https://doi.org/10.1086/678369

Mills, C.W. (1959). The Sociological Imagination. New York: Oxford University Press.

Nagel, T. (2005, Spring). The Problem of Global Justice. Philosophy \& Public Affairs, 33(2), 113-147. Blackwell Publishing, Inc.

Nussbaum, M.C., \& Cohen, J. (1996). For love of country? Boston: Beacon Press.

Rawls, J. (1999a). A Theory of Justice (rev. ed.). Cambridge, MA, Harvard University Press.

Rawls, J. (1999b). The Law of Peoples; with, The Idea of Public Reason Revisited. Cambridge, Massachusetts, London, England: Harvard University Press.

Rawls, J. (1993). Political Liberalism. New York: Columbia University Press.

Rawls, J. (2001). Justice as Fairness: A Restatement. (Erin Kelly, Ed.). Cambridge, MA, Harvard University Press.

Rawls, J. (2005). Political Liberalism (expanded ed.). New York: Columbia University Press.

Ríos, P.D. (1998). Los movimientos sociales de los años sesentas en Estados Unidos: un legado contradictorio. Sociológica, año 1, núm. 38. 1968. Significados y efectos sociales, septiembre diciembre. https://doi.org/10.2307/j.ctv86dh6v.10

Sen, A. (1999). Development as Freedom. Oxford: Oxford University Press.

Sen, A. (2009). The Idea of Justice. London: Allen Lane.

Sen, A. (1996). Humanity and Citizenship. In M.C. Nussbaum \& J. Cohen (Eds.), For love of country? Boston: Beacon Press. https://doi.org/10.1086/678369

Williams, H.L. (2014). The Law of Peoples. In J. Mandle \& D.A. Reidy (Eds.), A Companion to Rawls (First Edition). Chichester, West Sussex: John Wiley \& Sons. 